\title{
Factors Associated with Quality of Life in Adult Epilepsy Patients: a Hospital Based Study from South India
}

\author{
Shanmukhi. $S^{1}$, Sita Jayalakshmi..$^{2}$ and Anand. $B^{3}$ \\ ${ }^{1}$ Clinical Psychologist, Department of Neurology, Krishna Institute of Medical Sciences. Hyderabad. \\ Andhra Pradesh, India \\ ${ }^{2}$ Sita Jayalakshmi.S Neurologist, Department of Neurology, Krishna Institute of Medical Sciences. \\ Hyderabad. Andhra Pradesh, India \\ ${ }^{3}$ Anand. B (DNB) Psychiatrist, Institute of Mental Health (IMH), Erragadda, Hyderabad. Andhra Pradesh, \\ India
}

Correspondence should be addressed to: Shanmukhi.S; shanmuki@yahoo.com

Received date: 22 April 2014; Accepted date: 28 June 2014; Published date: 3 February 2015

Academic Editor: Hélio A G Teive

Copyright (C) 2015. Shanmukhi.S, Sita Jayalakshmi.S and Anand. B. Distributed under Creative Commons CC-BY 4.0

\begin{abstract}
Background: Epilepsy is a chronic condition which affects quality of life (QOL). QOL is considered as an important outcome measure and component of management in studies of adult epilepsy. Objective: To evaluate factors associated with quality of life in adult epilepsy patients. Materials and Methods: A cross-sectional study was performed to examine the quality of life in 560 adult patients with epilepsy. The data collected included detailed clinical and socio-demographic data, epilepsy details, psychiatric diagnosis (ICD-10 for Mental and behavioral disorders), Liverpool seizure severity scale (LSSS) and Quality of life in epilepsy (QOLIE-31) are assessed. Descriptive statistics-Percentages, ANOVA, Univariate odds and Multiple Logistic Regression analysis with step-down procedure were done. Results: Study population comprised 337 males and 223 females with mean age of $29.26+10.83$ (range 18-50) years. On Univariate Odds ratio (OR) (95\% CI) for single anti-epileptic drug (AED) 2.75(1.85 to 4.09) and absence of psychiatric diagnosis 1.60(1.02 to 2.53) are predictors for good QOL. On one-way ANOVA with QOLIE subscales, seizure frequency and psychiatric diagnosis were found to be statistically significant $(\mathrm{p}<0.01)$ but no significant interaction between them. On Logistic Regression step down procedure, psychiatric diagnosis (OR 95\% C.I) 7.29(1.65 to 32.10) and multiple AED 1.86(1.24 to 3.51) was found to be predicting factors for poor QOLIE. Conclusion: The presence of psychiatric diagnosis (Depression and Anxiety) was the strongest predictor of poor QOLIE patients. Early psychiatric evaluation and intervention would improve quality of life in epilepsy patients.
\end{abstract}

Keywords: Quality of life, epilepsy, factors, predicting factors

Cite this Article as: Shanmukhi.S, Sita Jayalakshmi.S and Anand. B (2015), " Factors Associated with Quality of Life in Adult Epilepsy Patients: a Hospital Based Study from South India," Research in Neurology: An International, Vol. 2015 (2015), Article ID 766328, DOI: 10.5171/2015.766328 


\section{Introduction}

Quality of life research has been performed in almost all areas of medicine, historically beginning with oncology and reaching also the field of neurology. Quality of life in epilepsy has become a critical measure in health care (Cramer 1994) due to the increased use in clinical research and practice (Hermann, 1993\& Jacoby, 1992).

Quality of life had given rise to numerous discussions and debates in health care since late 1980 throughout the world. QOL had under gone a marked change from well-being of patients with chronic health care problems to an important outcome measure. (Vickrey, 1993-94 \& Mihara, 1994).

Seizures in $70-80 \%$ of people who develop epilepsy are well controlled by antiepileptic drug (AED); treatment is clearly shown in epidemiological studies (Sander, 1993) and research shows that quality of life does not diminish very greatly in groups of well controlled epilepsy (Jacoby, 1992). In other $20-30 \%$ of groups whose seizures are chronic and intractable, the QOL may be less positive. However, it has been reported previously that there is a clear relationship between the severity of epilepsy and QOL; the impact of epilepsy on QOL is complex and may be mediated by a number of different factors (Collings, SJ. 1990 \& Collings, JA 1990) including patients own perceptions of themselves, their condition and its treatment.

The studies on factors influencing quality of life showed seizure frequency (Guekht. et al., 2007 \& Tlusta, et al., 2009) to be one of the most important factors along with comorbid psychiatric conditions (Tlusta, et al., 2009) and symptoms of depression (Canuet et al 2009) . Other determinants of quality of life were seizure worry (Loring, et al 2004) duration of disease (Canuet et al 2009) and employment (Tlusta, et al., 2009).

The importance on the application of quality of life assessment in research concerning epidemiology, clinical trials, quality assurance, and individual patient care are well investigated .In terms of epidemiology, the description of the quality of life of representative population samples helped in identifying poor QOL in a clinical population in comparison to a healthy reference group. In clinical studies, the effects of interventions in longitudinal and randomized cohort studies on QOL were investigated. In quality assurance programmes the use of QOL assessments was to capture the benefits of the care strategy in order to assess the QOL delivered and to improve the overall treatment of the patient in an institution. In individual care QOL helped to plan,monitor and evaluate individual care for that patient taking account the perceptions, wishes and priorities of the patient.

This study attempts to investigate factors associated with quality of life in adult epilepsy patients, also focusing in particular on the uses of QOL as an out-come measure on different dimensions of sociodemographic, type and treatment of epilepsy. The intention is to identify factors which cause good and poor quality of life and aims to provide useful information to improve their well-being.

\section{Method and Materials}

\section{Design and Sample}

A cross-sectional study was performed to examine quality of life in 560 adult epilepsy patients. Non Random consecutive sampling method was adopted. This group consisted of 337 males and 223 females (age range 1850). Each patient was interviewed and assessed by a clinical psychologist and neurologist. Informed consent was taken from all participants.

- Inclusion Criteria: Age between 1855years and having a definite diagnosis of epilepsy.

- Exclusion Criteria: Patients who had malignant epilepsy syndromes accompanied by a mental handicap, 
family history of psychiatry, psychosis, presence of severe psychiatric disturbances and nonepileptic attacks in epilepsy patients were excluded.

\section{Procedure and Instruments}

They were assessed on clinical, sociodemographic data, details on epilepsy, AED whether monotherapy or polytherapy. All the patients were interviewed on psychiatric problems and diagnosed according to the International Statistical Classification of Diseases and Related Health Problems 10th Revision (ICD10) for Mental and Behavioral disorders. The psychiatric diagnosis was made clinically by a qualified clinical psychologist for anxiety and depressive disorders. Clinical details of epilepsy were given by the neurologist. We used QOLIE -31 scale of quality of life which is a modified version of QOLIE-89(Quality of life in epilepsy).QOLIE-31 (Cramer, J.A., et al 1998) consists of 31 questions divided into 7groups (subscales). Liverpool seizure severity scale (LSSS) (Baker, G.A., et. al., 1991) was used to assess seizure severity. The scale assesses perception of seizure control and ictal postictal effects in two subscales.

In Quality of Life, the subscales which were assessed are seizure worry, overall quality of life (overall QOL), emotional wellbeing, Energy/fatigue, cognitive functioning, medication effects and social functioning. In the present study we considered the score of the each subscale and total score; higher score indicates better quality of life. The patients were divided into two groups separated by median $50(0-100$ scale) into $>50$ as good outcome and $<50$ as poor outcome on quality of life. This Division is an accepted procedure where cutoffs on an instrument are not given.

\section{Statistical Tests Used}

Descriptive statistics was done for sociodemographic data, seizure type, AEDs, QOLIE and psychiatric diagnosis. Analysis of variance (ANOVA's) one way was done for comparing the changes in seizure type and QOLIE subscale's. Multiple logistic regression analysis with step-down procedure was employed in data analysis. For ANOVA P value less than 0.01 was taken as significant and for Logistic Regression Odds Ratio with 95\% confidence interval were considered. SPSS package was used for analysis.

\section{Results}

Study population comprised of 337 males and 223 females with mean age of 29.78(1855) years. According to demographic data most of them were males, married residing in urban areas. The study shows patients were mostly educated either students or working nonprofessionals (Table I). Duration of epilepsy (mean value 9.36 years and SD - 8.) and Liverpool seizure severity scale (mean value of severity score 32.1 and SD-25.1) are continuous variables ranging from zero to maximum hence mean and standard deviations are given.

Table 1: Demographic Details and Qolie

\begin{tabular}{|l|c|c|c|}
\hline \multicolumn{1}{|c|}{ Characteristic } & No of Patients (\%) & Good (\%) & Poor (\%) \\
\hline $\begin{array}{l}\text { Gender } \\
\text { Male }\end{array}$ & $337(60 \%)$ & $284(84.2)$ & $53(15.8)$ \\
\hline Female & $223(40)$ & $183(82.1)$ & $40(17.9)$ \\
\hline
\end{tabular}

Shanmukhi.S, Sita Jayalakshmi.S and Anand. B (2015), Research in Neurology: An International, DOI: $10.5171 / 2015.766328$ 


\begin{tabular}{|l|c|c|c|}
\hline $\begin{array}{l}\text { Marital Status } \\
\text { Single }\end{array}$ & $257(45.8)$ & $205(79.7)$ & $52(20.3)$ \\
\hline Married & $303(54.1)$ & $262(86.4)$ & $41(13.6)$ \\
\hline $\begin{array}{l}\text { Residence } \\
\text { Urban }\end{array}$ & $356(63.6)$ & $292(82)$ & $64(18)$ \\
\hline Rural & $148(26.4)$ & $125(84.4)$ & $23(15.6)$ \\
\hline Semi urban & $56(10)$ & $50(89.2)$ & $6(10.8)$ \\
\hline $\begin{array}{l}\text { Education } \\
\text { Primary }\end{array}$ & $109(19.4)$ & $89(81.6)$ & $20(19.4)$ \\
\hline Secondary & $131(23.4)$ & $105(80)$ & $26(20)$ \\
\hline Intermediate & $83(14.8)$ & $65(78.3)$ & $18(21.7)$ \\
\hline Graduation & $146(26.2)$ & $114(78)$ & $32(22)$ \\
\hline Post-graduation & $45(8)$ & $35(77.7)$ & $10(22.3)$ \\
\hline Nil Education & $46(8.2)$ & $33(71.7)$ & $13(28.3)$ \\
\hline $\begin{array}{l}\text { Occupation } \\
\text { Laborer }\end{array}$ & $28(5.1)$ & $22(78.6)$ & $6(21.4)$ \\
\hline Agriculture & $40(7.1)$ & $28(70)$ & $12(30)$ \\
\hline Student & $129((23)$ & $96(74.4)$ & $33(25.6)$ \\
\hline Non-Professional & $105(18.7)$ & $82(78)$ & $23(22)$ \\
\hline Professional & $57(10.2)$ & $49(85.9)$ & $8(14.1)$ \\
\hline Business & $31(5.6)$ & $9(70.9)$ & $9(29.1)$ \\
\hline Housewives & $5(18.2)$ & $24(23.6)$ \\
\hline Others & $5(10.5)$ & $4(44.5)$ \\
\hline Nil occupation & & $24(40.7)$ \\
\hline
\end{tabular}

Most of epilepsy patients had no family history, on single AED, well controlled and partial (focal, local) seizures. Frequency of seizures were categorized into three groups, well controlled on $\mathrm{AED}$ (, refractory seizures (Refractory epilepsy may be defined as failure of adequate trials of two tolerated and appropriately chosen and used AED schedules to achieve sustained seizure freedom.) and nil seizures not on AEDs. Most of the patients show well controlled seizures 322 (57.5\%). (Table II).

Table 2: Epilepsy Characteristics:

\begin{tabular}{|l|c|c|c|}
\hline \multicolumn{1}{|c|}{ Characteristic } & No of Patients (\%) & Good (\%) & Poor (\%) \\
\hline Family History in Epilepsy & $443(79.1)$ & $331(74.7)$ & $112(25.3)$ \\
\hline Absent & $117(20.9)$ & $92(78.6)$ & $25(21.4)$ \\
\hline
\end{tabular}




\begin{tabular}{|l|c|c|c|}
\hline $\begin{array}{l}\text { AED } \\
\text { Single }\end{array}$ & $334(59.6)$ & $276(82.6)$ & $58(17.4)$ \\
\hline Multiple & $213(38)$ & $135(63.4)$ & $78(36.6)$ \\
\hline Nil AED & $13(2.4)$ & $12(92.3)$ & $1(7.7)$ \\
\hline $\begin{array}{l}\text { Frequency of Seizure } \\
\text { Well controlled Seizures }\end{array}$ & $322(57.5)$ & $262(81.4)$ & $60(18.6)$ \\
\hline Refractory seizures & $224(40)$ & $149(66.5)$ & $75(33.4)$ \\
\hline Nil seizures & $14(2.5)$ & $12(85.7)$ & $2(14.3)$ \\
\hline $\begin{array}{l}\text { Seizure Type } \\
\text { Partial l(focal, local) } \\
\text { seizures }\end{array}$ & $361(64.5)$ & $258(71.5)$ & $103(28.5)$ \\
\hline \begin{tabular}{l} 
Generalized Seizures \\
\hline
\end{tabular} & $199(35.5)$ & $165(82.9)$ & $34(17.1)$ \\
\hline
\end{tabular}

Psychiatric diagnosis was present in 36\% of our study population. Most of psychiatric problems were depression and anxiety. Depression is a major condition in $105(18.75 \%)$ epilepsy patients in this study. Out of 560 cases, 205 patients had psychiatric conditions out of these 45(22\%) cases had poor QOLIE (Table III). One way analysis of variance was done on seven sub scales of QOLIE i.e. seizure worry, overall QOLIE emotional well-being, energy/fatigue, cognitive functioning, medication effects, social functioning and seizure type. On ANOVA no significant difference was found between subscales and seizure frequency mainly on refractory seizures as shown in Table IV.

Table 3: Psychiatric Diagnosis and QOLIE

\begin{tabular}{|l|c|c|c|}
\hline Psychiatric Diagnosis & No of Patients & Good QOLIE \% & Poor QOLIE\% \\
\hline No Diagnosis & 355 & $(307) 86.4 \%$ & (48) $14.6 \%$ \\
\hline Depression & 105 & (75) $71.4 \%$ & (30) $28.6 \%$ \\
\hline Anxiety & 94 & (80) $85.1 \%$ & (14) $14.9 \%$ \\
\hline Others & 6 & (5) $83.3 \%$ & (1) $16.7 \%$ \\
\hline
\end{tabular}


Table 4: One way ANOVA between Refractory Seizure frequency Group \& Subscales of QOLIE

\begin{tabular}{|l|c|c|}
\hline Characteristic & F & Significance* \\
\hline Seizure worry & 23.899 & .000 \\
\hline Overall QOLIE & 34.077 & .000 \\
\hline Emotional well-being & 17.444 & .000 \\
\hline Energy/Fatigue & .529 & 0.468 \\
\hline Cognitive functioning & 21.57 & .000 \\
\hline Medication effects & 9.299 & .002 \\
\hline Social functioning & 37.55 & .000 \\
\hline
\end{tabular}

${ }^{*} \mathrm{p}<0.01$ was considered significant

Predictors of good QOLIE were single antiepileptic medication (AED) and absence of psychiatric diagnosis on Univariate analysis. (Table V). Male sex indicated Odds ratio (OR)

1.17 but $95 \%$ confidence intervals of OR $(0.75,1.84)$ were not significant similarly on marital status (single) indicated Odds ratio
(1.495) significant but confidence intervals of Odds ratio (1.029 -0.174$)$ were not significant. On multiple logistic regression steps down procedure, factors which are found to be significantly associated with poor quality of life were multiple AEDs and presence of a psychiatric diagnosis at step 8. Psychiatric diagnosis was the major predicting factor for poor QOLIE (Table VI).

Table 5: Predictors of Good QOLIE - Univariate Analysis

\begin{tabular}{|l|c|cc|}
\hline Character & Odds Ratio & \multicolumn{2}{|c|}{$95 \%$ C.I for Exp(B) } \\
\hline Single AED & Lower & Upper \\
\hline Absence of Psychiatric Diagnosis & 1.60 & 1.85 & 4.09 \\
\hline
\end{tabular}


Table 6: Multiple Logistic Regressions (Step- down procedure) for Poor QOLIE at Step 8

\begin{tabular}{|l|c|c|}
\hline \multirow{2}{*}{ Character } & Odds Ratio & \multicolumn{2}{|c|}{$95 \%$ C.I for Exp(B) } \\
\hline Multiple AED & 1.86 & $1.24-3.51$ \\
\hline Psychiatric Diagnosis & 7.29 & $1.656-32.103$ \\
\hline
\end{tabular}

\section{Discussion}

The purpose of our study was to identify factors influencing quality of life in epilepsy patients. According to the results, the study shows that factors associated with quality of life in adult epilepsy patients were psychiatric problems and AEDs. Absence of psychiatric problems and patients on single AED were associated with good quality of life and Psychiatric diagnosis (depression and anxiety) and multiple AEDs were strong predictors of poor quality of life. Previous work revealed that the most important determinants for patients with epilepsy were social and psychological aspects, effects of antiepileptic drugs and seizure frequency, which were determinants of poor QOL, scores (Suurmeijer, et al., 2001). This study shows no difference on the above mentioned factors on the score of QOL, though there was variation in seizure frequency. Another study by Yue L et al., (2011) indicated anxiety and seizure related variables as the strongest predictors of QOLIE among men.

In the present study depression and anxiety were prominent predictors for poor quality of life in epilepsy patients. Previous studies have also reported high prevalence of psychological and social disorders reported in-patients with epilepsy (Kogeorgos, et al., 1982). In a study by Lehrner et al., (1999) found depression was the single strongest predictor for each field of health -related quality of life in patients with temporal lobe epilepsy. There was a significant association with health related quality of life and depression which continued to exist even after controlling seizure frequency, seizure severity, and other psychosocial variables. Anxiety is a common consequence of the unpredictable nature of some epilepsies. (Guekht et al., 2007). People with epilepsy have been reported to be more prone to depression than those without epilepsy (Robertson et al., 1987). These studies support our finding that depression and anxiety were major determining factors for poor quality of life.

Herodes et al., (2001) indicated demographic variables such as age, sex and education as well as socio- economic status (SES) in determining the quality of life which was not significant. Leidy et al., (1993) reported that QOL differs across epilepsy patients with different clinical, demographic and socio economic variables. This is similar to our study single AED therapy showed good quality of life. With regard to clinical variables, multiple AED use was found to be a significant predictor of the quality of life poor scores, similar to the study by Suurmeijer et al., (2001). Seizure type was not a significant factor in the present study similar to other studies (Baker et al., 1997-98). The findings of our study are comparable to some studies where age, sex and education did not correlate significantly with the quality of life (Suurmeijer et al., 2001 \& Baker et al., 2001).

Previous studies have highlighted the employment difficulties faced by persons with epilepsy i.e. underemployment and unemployment has been identified as two of 
the most serious problems, they face also lower rates of marriages (Floyd, 1986 \& Rodin et al., 1972). The study by Djibuti and Shakarishvili (2003) revealed education as one of the strongest predictor of low quality of life. Unlike these studies according to our study most of the patients were either studying or employed in some profession though most of females happen to be housewives.

In conclusion, these findings show that psychiatric problems may be a potential challenge for people with epilepsy to cause poor QOL. Improving the patient's quality of life (QOL) is one of the most important goals of epilepsy management and it may be necessary to individualize interventions such as counseling and psychotherapy techniques to improve the QOL in epilepsy patients. The major advantage of the study is large number of epilepsy patients but limitation is a crosssectional study without control or follow-up. Our data also suggest multiple AED as powerful predictor of poor quality of life. The factor associated with QOL emphasizes the importance of effective treatment and alleviating anxiety and depression levels, which may improve the quality of life.

Abbreviations: International Classification of Disorders- (ICD-10), Liverpool seizure severity scale (LSSS) and Quality of life in epilepsy (QOLIE-31 \& 89), Antiepileptic drugs (AED) \& Analysis of variance (ANOVA's).

\section{References}

1. Baker, G.A, Smith, D.F., Dewey, M., Morrow, J., Crawford, P.M., \& Chadwick, D.W. (1991). The development of a seizure severity scale as an outcome measure in epilepsy. Epilepsy Res, 8(3): s 245-251.

2. Baker, G.A., Gagnon, D., \& McNotty, P. (1998). The relationship between seizure frequency, seizure type and quality of life: findings from three European countries. Epilepsy Res, 30:231-40.
3. Baker, G.A., Jacoby, A., Buck, D., Brooks, J., Potts, P., \& Chadwick, D.W. (2001). The quality of life of older people with epilepsy: findings from a UK community study. Seizure, 10:92-9.

4. Baker, G.A., Jacoby, A., Buck, D., Stalgis, C., \& Monnet, D. (1997). Quality of life of people with epilepsy: a European study. Epilepsia; 38:353-62.

5. Canuet, L., Ishii, R., Iwase $\mathrm{M}$, Ikezawa $\mathrm{K}$, Kurimoto R, Azechi M, Takahashi H, Nakahachi T, Teshima Y, Takeda M. (2009). Factors associated with impaired quality of life in younger and older adults with epilepsy. Epilepsy Res, 83 (1): 58-65.

6. Collings, J.A. (1990). Epilepsy and wellbeing. Soc Sci Med, 31:165-70.

7. Collings, S.J. (1990). Psycho social wellbeing and epilepsy: an empirical study. Epilepsia, 31:418-26.

8. Cramer, J.A (1994) .Quality of life for people with epilepsy. Neurol Clin, 12:1-13.

9. Cramer, J.A., Perrine, K., Devinsky, O., Bryant-Comstock, L., Meador, K., \& Hermann, B.P. (1998). Development and Cross-Cultural Translations of a 31-Item Quality of Life in Epilepsy Inventory. Epilepsia, 39(1): 81-88.

10. Djibuti, M \& Shakarishvili, R. (2003). Influence of clinical, demographic, and socio economic variables on quality of life inpatients with epilepsy: findings from Geargian study. J Neurol Neurosurg Psychiatry, 74:570-573.

11. Floyd, M. (1986). A review of published studies in epilepsy and employment. In: Edwards F, Espir M, Oxley J, Eds. Epilepsy and employment - a medical symposium on current problems and best practices. London: Royal Society of Medicine Services 1986.

12. Guekht, A.B., Mitrokhina, T.V., Lebedeva, A.V., Dzugaeva, F.K., Milchakova, L.E., Lokshina, O.B., Feygina, A.A., \& Gusev, E.I. 
(2007). Factors influencing on quality of life in people with epilepsy. Seizure. Mar; 16(2):128-33.

13. Hermann, B.P. (1993). Developing a model of quality of life in epilepsy: the contribution of neuropsychology. Epilepsia, 34(suppl 4): S14-21.

14. Herodes, M., Oun, A., Haldre, S., \& Kaasik, A.E. (2001). Epilepsy in Estonia: a quality of life study. Epilepsia, 42:1061-73.

15. Jacoby, A. (1992). Epilepsy and the quality of everyday life. Findings from a study of people with well-controlled epilepsy. Soc Sci Med, 43:657-66.

16. Kogeorgos, J., Fonagy, P., \& Scoff, D.F. (1982). Psychiatric symptoms patterns of chronic epileptics attending a neurological clinic: a controlled investigation. $B r \mathrm{~J}$. Psychiatry, 140:236-43.

17. Lehrner, J., Kalchmayr, R., Serles, W., Olbrich, A., Pataraia, E., Aull, S., Bacher, J., Leutmezer, F., Gröppel, G., Deecke, L., \& Baumgartner, C. (1999). Health-related quality of life (HRQOL), activity of daily living (ADL) and depressive mood disorder in temporal lobe epilepsy patients. Seizure, 8(2):88-92.

18. Leidy, N.K., Elixhauser, A., Vickrey, B., Means, E., \& Willian, M.K. (1993) Seizure frequency and the health-related quality of life of adults with epilepsy. Neurology, 53; 162-6.

19. Loring, D.W., Meador, K.J., \& Lee, G.P. (2004). Determinants of quality of life in epilepsy. Epilepsy Behav. 5 (6):976-80.

20. Mihara, T. (1994). Comprehensive assessment of outcome in 100 patients followed for over 2 years after resective surgery for temporal lobe epilepsy (in
Japanese). Shinkei Kenkyu No Shinpo, 38(5); 771-80.

21. Robertson, M.M., Trimble, M.R., \& Townsend, H.R.A. (1987). Phenomenology of depression in epilepsy. Epilepsia, 28:364-72.

22. Rodin, E., Rennick, P., Denerell, R., \& Lin, Y. (1972). Vocational and educational problems of epileptic patients. Epilepseia, 13:149-60.

23. Sander, JWAS. (1993). Some aspects of prognosis in the epilepsies: a review. Epilepsia, 34: 1007-16.

24. Suurmeijer, T.P., Reuvekamp, M.F., \& Alden Kamp, B.P. (2001). Social functioning psychological functioning and quality of life in epilepsy. Epilepsia, 42:1160-8.

25. Tlusta, E., Zarubova, J., Simko, J., Hojdikova, H., Salek, S., \& Vlcek, J. (2009). Clinical and demographic characteristics predicting QOL in patients with epilepsy in the Czech Republic: how this can influence practice. Seizure. Mar; 18 (2):85-9.

26. Vickrey, B.G, Hays, R.D., Rausch, R., Sutherling, W.W., Engel, J. Jr, \& Brook, R.H. (1994). Quality of life of epilepsy surgery patients as compared with -out patients with hypertension, diabetes, heart disease and/or depressive symptoms. Epilepsia, 35(3): 597607.

27. Vickrey, B.G. (1993). A procedure for developing a quality of life measure for epilepsy surgery patients. Epilepsia, 34 (Suppl 4): S22-7.

28. Yue, L., Yu, P.M., Zhao, D.H., Wu, D.Y., Zhu, G.X., Wu, X.Y., \& Hong, Z. (2011). Determinants of quality of life in people with epilepsy and their gender differences. Epilepsy Behav. 22(4):692-6. 